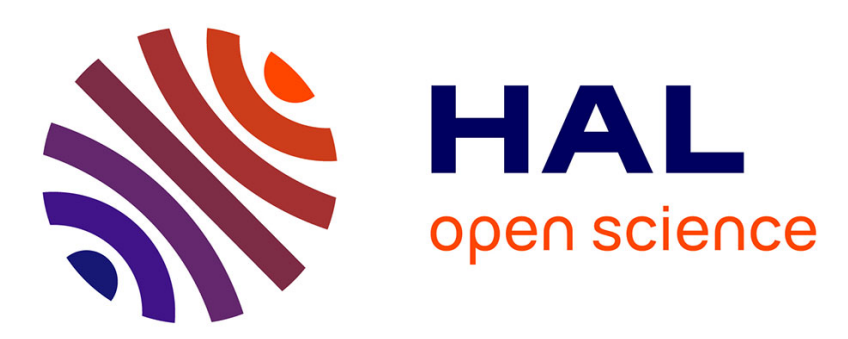

\title{
Experimental investigation of the wall dynamics of the A-pillar vortex flow
}

Benjamin Levy, Pierre Brancher

\section{To cite this version:}

Benjamin Levy, Pierre Brancher. Experimental investigation of the wall dynamics of the A-pillar vortex flow. Journal of Fluids and Structures, 2015, 55, pp.540-545. 10.1016/j.jfluidstructs.2015.03.020 . hal-01302191

\section{HAL Id: hal-01302191 https://hal.science/hal-01302191}

Submitted on 13 Apr 2016

HAL is a multi-disciplinary open access archive for the deposit and dissemination of scientific research documents, whether they are published or not. The documents may come from teaching and research institutions in France or abroad, or from public or private research centers.
L'archive ouverte pluridisciplinaire HAL, est destinée au dépôt et à la diffusion de documents scientifiques de niveau recherche, publiés ou non, émanant des établissements d'enseignement et de recherche français ou étrangers, des laboratoires publics ou privés. 


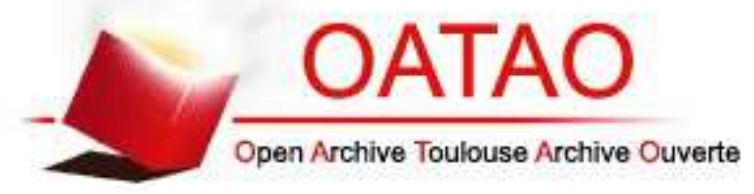

\section{Open Archive TOULOUSE Archive Ouverte (OATAO)}

OATAO is an open access repository that collects the work of Toulouse researchers and makes it freely available over the web where possible.

This is an author-deposited version published in : http://oatao.univ-toulouse.fr/ Eprints ID : 15685

To link to this article : DOI:10.1016/j.jfluidstructs.2015.03.020

URL : http://dx.doi.org/10.1016/j.jfluidstructs.2015.03.020

\section{To cite this version :}

Levy, Benjamin and Brancher, Pierre Experimental investigation of the wall dynamics of the A-pillar vortex flow. (2015) Journal of Fluids and Structures, vol. 55. pp. 540-545. ISSN 0889-9746

Any correspondence concerning this service should be sent to the repository administrator: staff-oatao@ listes-diff.inp-toulouse.fr 
Brief Communication

\title{
Experimental investigation of the wall dynamics of the A-pillar vortex flow
}

\author{
Benjamin Levy ${ }^{\mathrm{a}, \mathrm{b}, \mathrm{c}, \mathrm{d}, \mathrm{e}, *}$, Pierre Brancher ${ }^{\mathrm{b}, \mathrm{c}, \mathrm{d}, \mathrm{e}, \mathrm{f}}$ \\ a Department of Engineering Science, University of Auckland, 70 Symonds Street, 1010 Auckland, New Zealand \\ ${ }^{\mathrm{b}}$ Université de Toulouse, Allée Camille Soula, F-31400 Toulouse, France \\ ' INPT, Allée Camille Soula, F-31400 Toulouse, France \\ ' UPS, Allée Camille Soula, F-31400 Toulouse, France \\ e IMFT (Institut de Mécanique des Fluides de Toulouse), Allée Camille Soula, F-31400 Toulouse, France \\ ${ }^{\mathrm{f}}$ CNRS, F-31400 Toulouse, France
}

Keywords:

A-pillar

Fluid-structure interaction

Aero-acoustic

Excitation

Vortex

Automobile

\begin{abstract}
A B S T R A C T
The influence of the A-pillar vortex on the wall flow of the side window of a car is investigated experimentally using a $30^{\circ}$ dihedron model. The measurement of the unsteady pressure at the wall provides a map of the pressure fluctuation intensity, and a spectral analysis is performed to track the dominant frequencies of the wall pressure fluctuations. The wall flow generated by the vortex structure that develops parallel to the side-wall is characterised by means of particle image velocimetry (PIV). Its structure is analysed and compared to cross-sections of the A-pillar vortex in order to identify the different separation and reattachment lines. A comparison of the field of turbulent kinetic energy obtained by PIV with the map of the pressure fluctuations shows a correlation between the structure of the A-pillar vortex and the pressure fluctuations. It is found that the dominant wall pressure fluctuations are located at the secondary separation line, whereas the primary reattachment line does not show any significant pressure variations, that the A-pillar vortex will not naturally break down and that discrete vortices may be associated with the pressure fluctuations.
\end{abstract}

\section{Introduction}

The A-pillar vortex is generated at the junction between the windshield and the front side window when a road vehicle is in motion. The upstream flow bypassing the windshield rolls into an intense three-dimensional coherent structure which interacts with the side window. Besides increasing the drag of the vehicle (Hucho, 1998), one consequence of the A-pillar vortex is to generate a source of aeroacoustic noise perceived inside the vehicle (Hoshino and Kato, 2002). The noise level inside a car can be perceived as a criterion of quality which can impact the commercial success of a vehicle. Consequently, many studies have tried to quantify or to control its aeroacoustic contribution. Nevertheless, some fundamental aspects of the flow dynamics are still not clearly understood.

The topology of the vortex structure was partly identified by (Watanabe et al., 1978; Haruna et al., 1990) who highlighted the existence of regions of separation and reattachment on the wall. Later, most of the studies have focused on the impact of

\footnotetext{
* Corresponding author at: Department of Engineering Science, University of Auckland, 70 Symonds Street, 1010 Auckland, New Zealand. Tel./fax: +64 0224203881. E-mail address: benjamin.levy@hotmail.fr (B. Levy).
} 
side mirrors (Ono et al., 1999; Watkins and Oswald, 1999; Zimmer, 2004), the influence of the yaw angle (Alam et al., 2003; Murad et al., 2004; Howel et al., 2009), the modification of the A-pillar radius of curvature (Ono et al., 1999; Gohlke et al., 2010) or strategies for active flow control (Lehugeur, 2007; Lehugeur et al., 2010). It has been identified that an idealised geometry with sharp corner would create a more defined vortex structure than the one observed on a real road vehicle. The aerodynamic pressure applied on the side window or panel is correlated to the yaw angle and the free stream turbulence. All these past studies have emphasised the complexity and numerous parameter of the A-pillar flow. The detailed analysis of the topology and dynamics of the A-pillar vortex created by a generic bluff body, namely a $30^{\circ}$ dihedron, was the subject of multiple PhD dissertations over the past decade (Hoarau, 2006; Lehugeur, 2007; Levy, 2009), and has only been published relatively recently (Hoarau et al., 2008; Gilliéron et al., 2010; Levy and Brancher, 2013), as well as Howel et al. (2009) and Passmore et al. (2010). The A-pillar vortex flow is found to be composed of a primary vortex and a secondary, counterrotating vortex of lower intensity and smaller dimensions. The center of the primary vortex shifts away from the wall as it develops along the edge of the A-pillar while the secondary vortex remains near the wall. Despite erratic meandering, it has been shown that the primary vortex core displays a low-frequency motion of precession around its time-averaged position.

In parallel to these works on the flow dynamics, other studies focused on the acoustics. Lawson et al. (2008) used a full scale automobile to map the field of pressure coefficient on the side window. Besides observing significant discrepancy between wind tunnel and road testing results, their map shows a decreasing pressure coefficient $C_{p}$ as the measurements were made closer to the A-pillar. The same observation was made by Howel et al. (2009), who also pointed out at the existence of two peaks of unsteady pressure as the vortex structure grew in size. It has been predicted numerically that the pressure fluctuation level is larger where the $C_{p}$ level is lower (Ono et al., 1999). Recent development of computational fluid dynamics and computational aero-acoustics models has allowed to decompose the perceived noise as a function of their sources: the trailing edge flow perturbations and the turbulent boundary layer (Murad et al., 2013). The surface noise signature was predicted using a Lattice Boltzmann method.

Nevertheless, no correlation has ever been made to our knowledge between the detailed structure of the A-pillar vortex obtained from particle image velocimetry, planes parallel and perpendicular to the side panel, and the pressure fluctuations at the surface of the side window. This is the aim of the present paper, which presents an analysis of the wall pressure fluctuations correlated to particle image velocimetry measurements.

\section{Experimental set-up}

The experimental model is the same as in Levy and Brancher (2013). It is composed of a simplified geometry, namely a dihedron at $30^{\circ}$ angle fixed on a reversed Ahmed body, replacing what is classically the back of the body (Fig. 1). The characteristic length associated with the model, defined as the square root of the apparent cross-section, is $L_{0}=0.336 \mathrm{~m}$.

The experiments were conducted in the S1 wind tunnel (Eiffel type) at the Institut de Mecanique des Fluides de Toulouse. One particularity of this type of wind tunnel is to have an open test section. The diameter of the flow inlet is $2.4 \mathrm{~m}$ and the distance to the flow outlet is $1.9 \mathrm{~m}$. The turbulent intensity is less than $0.3 \%$. The model was fixed on a mast, $1.5 \mathrm{~m}$ above the ground, at the centre of the test section. The velocity of the air flow was $U_{0}=8 \mathrm{~m} / \mathrm{s}$, which corresponds to a typical Reynolds number for the experiments of $\mathrm{Re}=1.7 \times 10^{5}$. The typical Reynolds number for a road vehicle is between $10^{6}$ and $10^{7}$, however LES simulation compared to experimental data has shown that Reynolds numbers greater than $10^{4}$ have little impact on the topology and flow dynamics of a simplified road vehicle with sharp edges (Alam et al., 2003; Krajnović and Davidson, 2003, 2004).

Particle Image Velocimetry (PIV) at a frequency of $4 \mathrm{~Hz}$ was used for the experimental data acquisition of the time averaged flow field. 1000 image pairs were acquired for each PIV plane, which proved to be sufficient for a convergence of the averaged flow field. Measurements were made in different sets of PIV planes, parallel to the side wall. The nearest set to the wall is at a minimum gap distance of $0.006 L_{0}$ between the laser sheet and the wall surface (Fig. 1). The equipment used for the PIV is a Quantel Laser CFR 200 with $2 \times 200 \mathrm{~mJ}$ cavities operating at a frequency of $4 \mathrm{~Hz}$ and a PCO Sensicam camera with a resolution of $1280 \times 1024$ pixels mounted with a $55 \mathrm{~mm}$ Nikon lens. For the seeding of the flow,

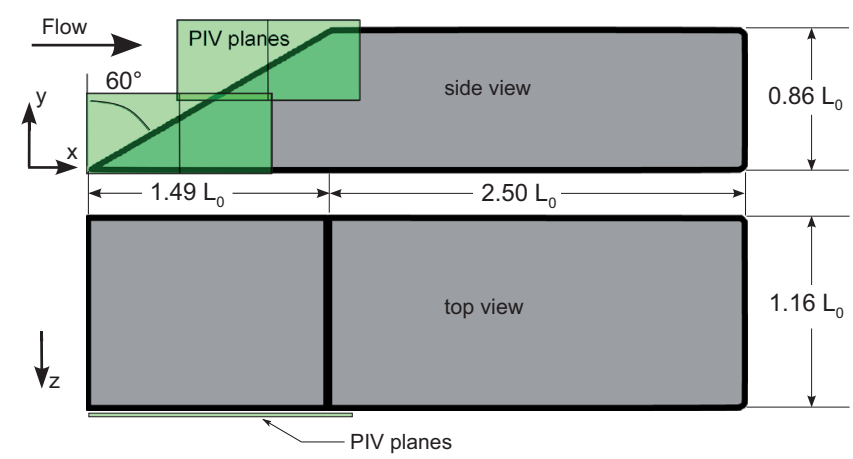

Fig. 1. Geometry and dimensions of the model; position of a set of four PIV planes parallel to the side wall. 
Di-Ethyl-Hexyl-Sebacat (DEHS) with particles of diameter 0.5-1.5 $\mu \mathrm{m}$ and a time response of about $25 \mu$ s (Raffel et al., 2007) was used. The flow was analysed by cross-correlating 50\% overlapping windows of $16 \times 16$ pixels, yielding fields of $160 \times 128$ with a spatial resolution of $1.25 \mathrm{~mm}\left(0.00375 \mathrm{~L}_{0}\right)$. Less than $2 \%$ of the calculated vectors were detected as outliers using a sort based on the norm, the signal-to-noise ratio, and a median test filter. These vectors were replaced using a second-order least-square interpolation scheme. There was a $2.4 \%$ uncertainty on the instantaneous data which were then averaged over 1000 frames. The uncertainties were estimated using 95\% confidence interval without a normal distribution assumption, according to Benedict and Gould (1996). The same method and equipment had been successfully used in the past by Perrin et al. (2007) and Levy and Brancher (2013).

The pressure fluctuations were measured by a Bruel and Kjaer 1/4" Type 4135 microphone. The microphone was inserted in a wall cavity located inside the model. From the outside, only a microscopic pinhole of diameter $0.7 \mathrm{~mm}\left(0.0021 L_{0}\right)$ was visible and linked the surface pressure to the microphone. Such setup avoids having an exposed flush-mounted microphone as well as avoids any alteration of the surface flow and was first introduced by Blake (1970). Measurements were made at 105 different locations scattered on the side panel of the model at a frequency of $22.05 \mathrm{kHz}$. The open circuit frequency response of the microphone is $4 \mathrm{~Hz}$ to $100 \mathrm{kHz}$, for a dynamic range of $42-172 \mathrm{~dB}$ or $1.6 \mathrm{mv} / \mathrm{Pa}$ and the accuracy of the acquisition chain is $\leq 0.5 \mathrm{~Pa}$. The time length for each recording was $30 \mathrm{~s}$.

\section{Results}

\subsection{Wall pressure}

The analysis of the pressure on the side wall provides two significant results. First, the pressure coefficient, $C_{p}=$ $\left(P-P_{0}\right) /\left(\frac{1}{2} \rho U_{0}^{2}\right)$, matches the one recorded around a road vehicle (Lawson et al., 2008) in terms of magnitude and spatial repartition. The largest pressure drop is recorded near the upstream tip of the dihedron with a reduction of pressure drop further downstream from the tip and the A-pillar junction (Fig. 2(a)). The same observation, with a $C_{p}$ of same magnitude, was made by Murad et al. (2013) despite using a model with a rounded junction. The pressure coefficients are of similar magnitude than the ones recorded by Howel et al. (2009), who performed their experiments at Reynolds number of an order of magnitude greater than the present investigation. Second, the pressure fluctuation field, measured by the root mean square of the time-resolved pressure signal $P_{R M S}$, displays a different tendency than the $C_{p}$. It is observed that the maximum values of $P_{R M S}$ are not located at the A-pillar junction but significantly below (Fig. 2(b)). The maxima form distinct patches with local extrema due to the low spatial resolution of the unsteady pressure measurements in this specific region (Fig. 2(c)). In spite of this spurious effect, the maxima are all aligned and it can be assumed that the maximum $P_{R M S}$ describes a line inclined by approximately $24^{\circ}$ from the $x$-axis (dashed line in Fig. 2(b)).

A spectral analysis of the pressure signal is performed using the Matlab Welch's power spectral density estimate function. The results at four different locations along the A-pillar junction, designated as $\mathrm{N}_{1-4}$ in Fig. 2(c), are displayed in Fig. 3(a). Near the front of the model, the $\mathrm{N}_{1}$ spectrum displays a small, wide, peak around $300 \mathrm{~Hz}$, which corresponds to a Strouhal number $S t=f L_{0} / U_{0}$ of approximately 12.6. Hoarau et al. (2008) observed at the same frequency a high coherence of

(a)

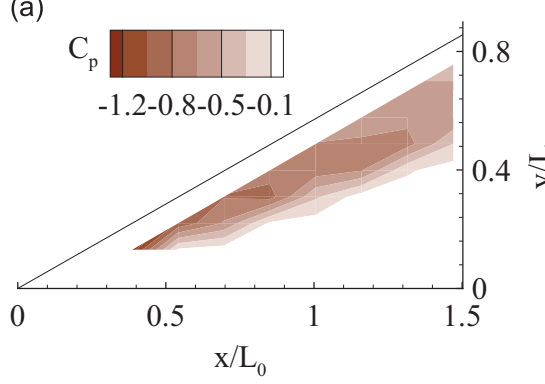

(b)

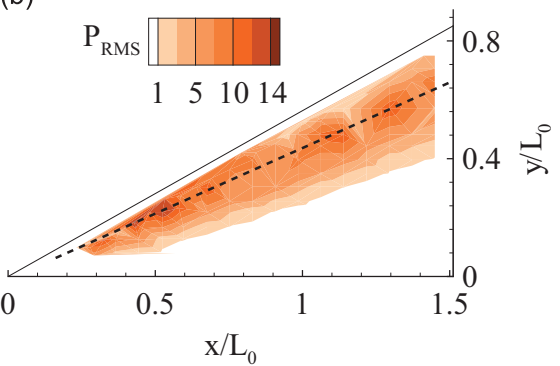

(c)

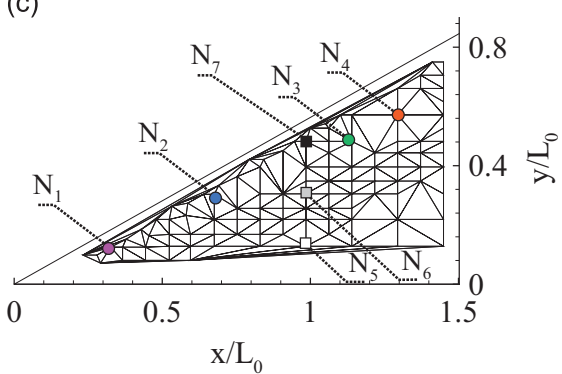

Fig. 2. (a) Field of wall pressure coefficient $C_{p}$; (b) field of root mean square pressure $P_{R M S}$ in Pa; the dashed line represents a line of maximum $P_{R M S}$; (c) mesh grid from the 108 pressure measurements; $\mathrm{N}_{1-7}$ marks the location of seven specific nodes. 
(a)

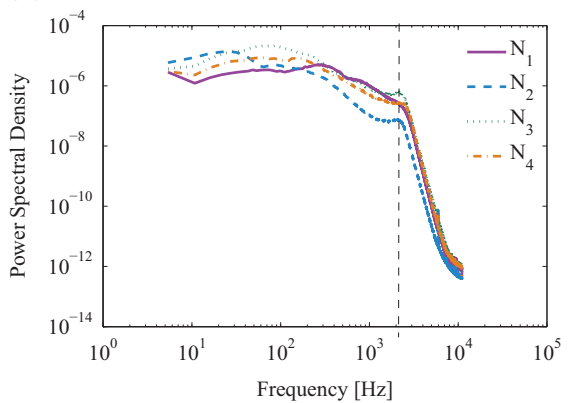

(b)

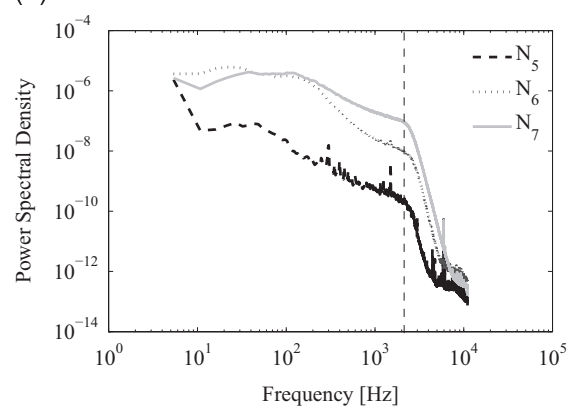

Fig. 3. Log-log Power spectral density of pressure fluctuations at the seven locations $\mathrm{N}_{1-7}$ on the side wall.

(a)

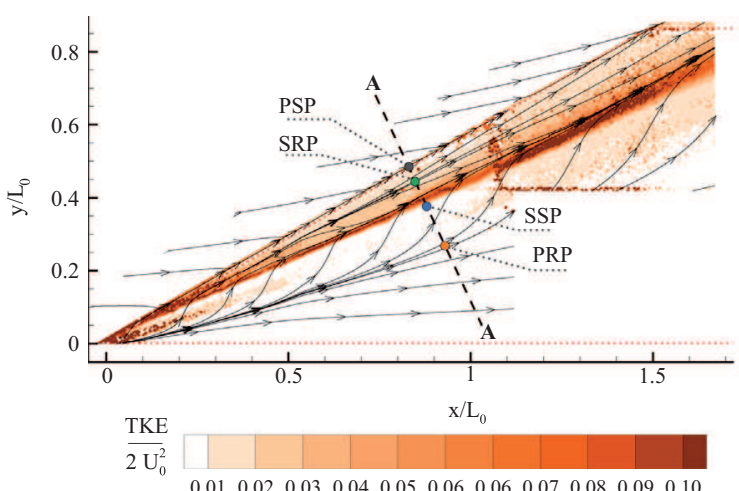

(b)

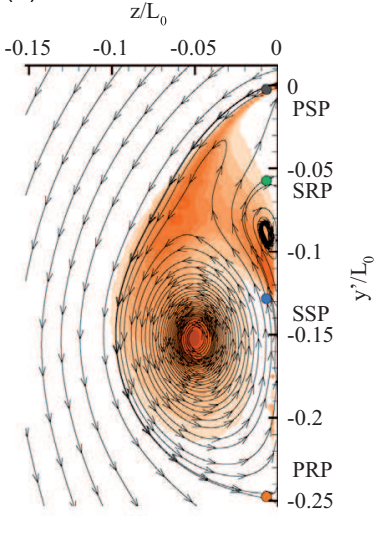

Fig. 4. (a) Normalised turbulent kinetic energy field parallel to the wall at a distance of $0.006 L_{0}$ and streamlines. The red dotted line outlines the shape of the model, the black dashed line localises the PIV plane normal to the wall and to the axis of the A-pillar vortex as in Levy and Brancher (2013). (b) Section "A-A", collinear to the $y^{\prime}$-axis, $25^{\circ}$ inclined from the $y$-axis; normalised turbulent kinetic energy field in the plane perpendicular to the wall. Color dots mark the location of the primary separation point (PSP), the secondary separation point (SSP), the primary reattachment point (PRP) and the secondary reattachment point (SRP). (For interpretation of the references to color in this figure caption, the reader is referred to the web version of this article.)

low-magnitude pressure signals on the side panel, on a similar model with slanted sides. However, a representative length scale associated with this frequency, $f L_{1} / U_{0} \approx 1$, leads to $L_{1} \approx 0.08 L_{0}$ which does not match any characteristic length of our model, unlike Hoarau et al. (2008). The phenomenon inducing this frequency does not persist along the A-pillar as it cannot be found on any other recordings. It might be linked to the specific dynamics of the flow at the very beginning of the Apillar, the lack of a robust vortex structure guiding the flow fluctuations at that stage preventing their frequencies to propagate downstream. A Strouhal of similar value was measured by Sims-Williams et al. (2006) on the C-pillar vortex dynamics and was identified as corresponding to the rate of discrete vortices production. Consequently, we can emit the hypothesis that a similar phenomenon may take place along the A-pillar but is only recorded at the ignition point of the Apillar vortex due to its comparative small scale.

As the primary and secondary vortex structures develop along the A-pillar, a wide range of frequencies between $10 \mathrm{~Hz}$ and $450 \mathrm{~Hz}$, which correspond to $\mathrm{St}=0.42$ and 18.9, are recorded with similar levels of intensity. A frequency of approximately $13 \mathrm{~Hz}, \mathrm{St}=0.55$, can be associated with a representative length scale of the order of the full length of the A-pillar vortex. Hoarau et al. (2008) raised the hypothesis that it could be associated with the meandering of the vortex structure. However, a previous study by Levy and Brancher (2013) has identified the meandering of the primary vortex for the exact same configuration to be of much lower frequency, namely $1-2 \mathrm{~Hz}$ or $\mathrm{St}=0.042-0.084$.

A relative peak of higher frequency, at lower power density levels, is recorded at $2250 \mathrm{~Hz} \pm 5 \%$, which corresponds to $\mathrm{St}=94.5$. It also defines the beginning of a logarithmic decrease of the power spectral density. Yet, a distinct frequency can be identified at $5940 \mathrm{~Hz}$, which corresponds to $\mathrm{St}=249.5$. The power spectral density of pressure fluctuations at three measuring points distributed along a vertical line (points $\mathrm{N}_{5-7}$ in Fig. 2(c)) shows the attenuation of the $2250 \mathrm{~Hz}$ frequency limit as the measurements are made further away from the A-pillar junction (Fig. 3(b)). Based on this result, we can make the assumption that this high frequency fluctuation originates at the A-pillar junction and that it is a localised phenomenon. Also, no well-defined frequency can be identified from the power spectral density plot, which emphasises the complexity of the A-pillar flow. The wall surface pressure fluctuation is mainly the result of multiple excitations in the frequency range 
$\leq 2250 \mathrm{~Hz}$. This frequency could be resulting from the turbulence emanating from the shear layer and evolving in the Apillar vortex (Hoarau et al., 2008).

\subsection{Wall flow}

To understand the origin of the pressure fluctuations on the side panel, we performed multiple PIV acquisition in planes parallel to the surface (Fig. 1). The streamlines obtained from the PIV measurements close to the wall display the conical shape of the A-pillar vortex tube and its inclination of approximately $25^{\circ}$ from the $x$-axis (Fig. 4(a)). The trace of the streamlines confirms that the separation and reattachment points observed in the cross-sections of the A-pillar vortex analysed in Levy and Brancher (2013) correspond to separation and reattachment lines extending along the side wall.

This is in agreement with past studies on real road vehicles (Haruna et al., 1990; Gaylard, 2007), which justifies the relevance of the $30^{\circ}$ dihedron as a generic model to reproduce the A-pillar vortex flow.

The A-pillar vortex is characterised by the presence of an axial flow. PIV measurement in planes parallel to the wall and normal to the vortex axis allows the swirl number $S$, defined as the ratio of the local azimuthal velocity and the axial velocity, to be estimated. This non-dimensional parameter predicts the stability of vortices with axial flow (Billant et al., 1998) and particularly defines that vortex breakdown is observed when the Swirl number is $S>\sqrt{2}$. The axial velocity at various locations along the A-pillar vortex axis was obtained with the present set-up and multiple sets of PIV planes at various gap distances from the side wall (data not shown). The azimuthal velocity component is obtained from the previously published results (Levy and Brancher, 2013). For the present investigation, the swirl number of the A-pillar primary vortex is estimated between 0.85 and 0.97 . Though the criterion for vortex breakdown has been experimentally found for free, unbounded vortices with axial flow, the present estimate suggests that vortex breakdown is not active for the A-pillar vortex flow. Therefore it can be conjectured that the measured velocity fluctuations at the wall are the results of unsteadiness of the Apillar vortex and its surrounding flow with a physical origin instead of a vortex breakdown phenomenon.

These regions of unsteadiness can be identified by analysing the structure of the turbulent kinetic energy (TKE) field in the vicinity of the side wall (Fig. 4(a)). A well defined straight line of high turbulent kinetic energy inclined by $24^{\circ}$ from the $x$-axis is observed. By comparison with a perpendicular cross-section of the vortex (Fig. 4(b)), this line is identified as corresponding to the mean position of the secondary separation line. Above the secondary separation line, the TKE is five times lower than along the separation line. Below this line, the magnitude of TKE is almost negligible and the primary reattachment line does not generate any significant fluctuations near the wall despite the meandering of the primary vortex.

By comparison of this result with the map of maximum values of $P_{R M S}$ (Fig. 2(b)), we observe that the line of maximum fluctuating kinetic energy which has been identified as the secondary separation line matches the line of maximum $P_{R M s}$. We conclude that the wall flow lying between the primary vortex and secondary vortex, identified as the secondary separation line, is responsible for producing the main pressure fluctuations at the wall.

\section{Conclusion}

Based on the premise that the A-pillar vortex is generating noise inside a road vehicle, we have investigated the aerodynamic structure responsible for this perturbation. The results of the present study have let us identify the origin of the main side panel excitation. The side panel of our model possesses a well-defined region of excitation. Correlated to the results published by Levy and Brancher (2013), we identified the $P_{R M S}$ to be aligned with the secondary separation line localised between the primary and the secondary vortex.

The PIV data obtained during this study provides the axial velocity of the A-pillar which, combined with the azimuthal velocity, defines the robustness of a vortex. The A-pillar vortex will not naturally break down as its Swirl number is lower than $\sqrt{2}$.

Finally, through a frequency analysis, it was found that the frequencies of fluctuating pressure were of a different magnitude than the primary vortex precession displacement frequency. These fluctuations are emanating at the A-pillar corner and no representative length scales could be associated with these frequencies. Near the onset of the A-pillar vortex, a frequency that corresponds to $\mathrm{St}=12.6$ was recorded and could be the results of discrete vortices. However, this hypothesis could not be visually verified.

\section{References}

Alam, F., Watkins, S., Zimmer, G., 2003. Mean and time-varying flow measurements on the surface of a family of idealised road vehicles. Experimental Thermal and Fluid Science 27, 639-654.

Benedict, L.H., Gould, R.D., 1996. Towards better uncertainty estimates for turbulence statistics. Experiments in Fluids 22, 129-136.

Billant, P., Chomaz, J., Huerre, P., 1998. Experimental study of vortex breakdown in swirling jets. Journal of Fluid Mechanics 376, $183-219$.

Blake, W.K., 1970. Turbulent boundary-layer wall-pressure fluctuations on smooth and rough walls. Journal of Fluid Mechanics 44, 637-660.

Gaylard, A., 2007. Cfd simulation of side glass surface noise spectra for a bluff suv. SAE Transactions 115, 99-115.

Gilliéron, P., Leroy, A., Aubrun, S., Audier, P., 2010. Influence of the slant angle of 3d bluff bodies on longitudinal vortex formation. Journal of Fluids Engineering 132, 051104.

Gohlke, M., Beaucoin, J., Amielh, M., Anselmet, F., 2010. Shape influence on mean forces applied on a ground vehicle under steady cross-wind. Journal of Wind Engineering and Industrial Aerodynamics 98, 386-391. 
Haruna, S., Nouzawa, T., Kamimoto, I., 1990. An experimental analysis and estimation of aerodynamic noise using a production vehicle. SAE Transactions, $667-680$.

Hoarau, C., 2006. Mesures multipoints pression - vitesse pour l'analyse de l'aérodynamique d'écoulements décollés instationnaire - Application aux véhicules terrestres (Ph.D. thesis). Université de Poitiers.

Hoarau, C., Borée, J., Laumonier, J., Gervais, Y., 2008. Unsteady wall pressure field of a model A-pillar conical vortex. International Journal of Heat and Fluid Flow 29, 812-819.

Hoshino, H., Kato, H., 2002. A new objective evaluation method of wind noise in a car based on human hearing properties. Acoustical Science and Technology 23, 17-24.

Howel, J., Fuller, J., Passmore, M., 2009. The Effect of Free Stream Turbulence on A-pillar Airflow. SAE Technical Paper 2009-01-0003.

Hucho, W.H., 1998. Aerodynamics of Road Vehicles, 4th edition, SAE.

Krajnović, S., Davidson, L., 2003. Numerical study of the flow around the bus-shaped body. Journal of Fluids Engineering 125, 500-509.

Krajnović, S., Davidson, L., 2004. Large-Eddy Simulation of the Flow around Simplified Car Model. SAE Technical Paper 2004-01-0227.

Lawson, A., Sims-Williams, D., Dominy, R., 2008. Effects of on-road turbulence on vehicle surface pressures in the A-pillar region. SAE International Journal of Passenger Cars-Mechanical Systems 1, 333-340.

Lehugeur, B., 2007. Caractérisation et contrôle des structures tourbillonnaires longitudinales en aérodynamique automobile (Ph.D. thesis). Université Pierre et Marie Curie.

Lehugeur, B., Gilliéron, P., Kourta, A., 2010. Experimental investigation on longitudinal vortex control over a dihedral bluff body. Experiments in Fluids 48 , 33-48.

Levy, B. 2009. Analyse et contrôle de l'écoulement de montant de baie (Ph.D. thesis). Université Paul Sabatier, Toulouse III.

Levy, B., Brancher, P., 2013. Topology and dynamics of the A-pillar vortex. Physics of Fluids 25, 037102.

Murad, N., Naser, J., Alam, F., Watkins, S., 2004. Simulation of Vehicle A-Pillar Aerodynamics Using Various Turbulence Models. SAE Paper 0231, pp. 55-70.

Murad, N., Naser, J., Alam, F., Watkins, S., 2013. Computational fluid dynamics study of vehicle A-pillar aero-acoustics. Applied Acoustics 74, 882-896.

Ono, K., Himeno, R., Fukushima, T., 1999. Prediction of wind noise radiated from passenger cars and its evaluation based on auralization. Journal of Wind Engineering and Industrial Aerodynamics 81, 403-419.

Passmore, M., Spencer, A., Wood, D., Jowsey, L., 2010. The Application of Particle Image Velocimetry in Automotive Aerodynamics. SAE Technical Paper 2010-01-0120.

Perrin, R., Cid, E., Cazin, S., Sevrain, A., Braza, M., Moradei, F., Harran, G., 2007. Phase-averaged measurements of the turbulence properties in the near wake of a circular cylinder at high Reynolds number by 2C-PIV and 3C-PIV. Experiments in Fluids 42, 93-109.

Raffel, M., Willert, C.E., Wereley, S.T., Kompenhans, J., 2007. In: Particle Image Velocimetry-A Practical Guide. Springer. ISBN: 978-3-540-72308-0.

Sims-Williams, D.B., Kaye, S., Watkins, S., 2006. Periodic Structures within the Formation Region of Trailing Vortices. SAE Technical Paper $2006-01-1032$. Watanabe, M., Harita, M., Hayashi, E., 1978. The Effect of Body Shapes on Wind Noise. SAE Paper.

Watkins, S., Oswald, G., 1999. The flow field of automobile add-ons with particular reference to the vibration of external mirrors. Journal of Wind Engineering and Industrial Aerodynamics 83, 541-554.

Zimmer, G., 2004. A Study of Passenger Car A-Pillar Vortex Effects Using Different Experimental Methods (Ph.D. thesis). RMIT University. 